WellBeing International

WBI Studies Repository

1986

\title{
The Case Against the Use of Animals in Science
}

Donald J. Barnes

The National AntiVivisection Society

Follow this and additional works at: https://www.wellbeingintlstudiesrepository.org/acwp_arte

Part of the Animal Experimentation and Research Commons, Animal Studies Commons, and the Bioethics and Medical Ethics Commons

\section{Recommended Citation}

Barnes, D.J. (1986). The case against the use of animals in science. In M.W. Fox \& L.D. Mickley (Eds.), Advances in animal welfare science $1986 / 87$ (pp. 215-225). Washington, DC: The Humane Society of the United States.

This material is brought to you for free and open access by WellBeing International. It has been accepted for inclusion by an authorized administrator of the WBI Studies Repository. For more information, please contact wbisr-info@wellbeingintl.org.

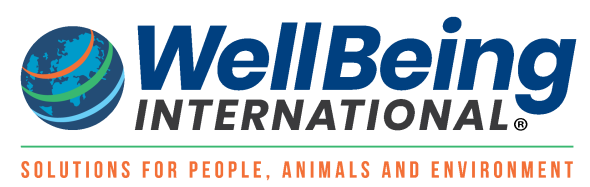




\section{THE CASE AGAINST THE USE OF ANIMALS IN SCIENCE ${ }^{1}$}

\section{Donald J. Barnes ${ }^{2}$}

I was very good at my job as an experimental psychologist, Principle Investigator; Chief, Performance Decrement Function; Survivability/Vulnerability Branch; Radiobiology Division, United States Air Force School of Aerospace Medicine; Brooks Air Force Base, Texas. I received many Outstanding performance ratings, and was promoted rapidly to an administrative position. My office was far removed from the laboratory, from the pain and suffering of non-human animals; I did not have to hear their screams, to see them struggle against the bonds of restraint, to watch them languish in the spotlessly clean stainless steel cages, separated from their fellows as well as from their natural environment. I could order them trained, order their deaths, expect the data print-out sheets which would serve as their death certificates, write a paper and wait for the recognition which would move me another step from the laboratory and another rung up the professional ladder. In the process, I could routinely sign the assurance of compliance with the Animal Welfare Act; just one more signature in a series of bureaucratic procedures. I had no reason to admit to causing the animals pain, so I did not. Who was to know? Who was to care?

As a scientist long committed to the understanding, prediction, and control of biological, physiological, and behavioral events, I have no objection to the animal as a legitimate focus of science. As a parent, a son, a sibling, and the proud recipient of unconditional positive regard from a few special people, I am vitally interested in matters of health and in the most ethically efficient use of available resources. As a member of a species which has evolved sufficiently to allow the relatively broad perspective of a "web of life" and at least a rudimentary concept of altruism, I have laboriously struggled against my individual egoism in an attempt to meet greater responsibilities to my fellow humans, to other animals, and to the planet which gives succorance to us all.

Although I regard the animal as a legitimate focus of research, I am irrevocably opposed to vivisection, the practice of inducing disease or trauma in a healthy animal for the hypothetical sake of another animal or another species of animal, for there is but one rationalization for such research: "The ends justify the means." 
The more knowledgeable and astute among you will realize that I've made my point and should retire, but I do not enjoy the luxury of addressing you as tabulae rasa, nor do you have the luxury of being so. I do not insult you; on the contrary, I pay you the respect of challenging you to break the bonds of conditioning to enjoy the freedom of innovative thought.

If I were you, I might be thinking, "This guy is twice as pompous as William F. Buckley and only half as bright!" And you would be half-right at most, for I am not pompous, I am bitterly embarrassed. Embarrassed because i spent 44 years of my life believing that non-human animals were mine to exploit, bitter because no one helped me find my way out of the anthropocentrism which ostensibly justified my behavior, bitter because my own background imbued me with a "conditioned ethical blindness" which is one more disease which cannot be cured through the use of nonhuman animals in the laboratory.

As a very young boy, I was given a bounty for every "varmit" I shot or trapped, for they competed with our livelihood as small farmers during the Depression. I was rewarded for killing "game" for the table, for catching fish for our consumption. I was taught to kill the biggest buck and to catch the most fish. I was taught to raise animals for market, and I was taught to butcher them and enjoy their flesh. Finally, I was taught to use them in experiments, and I spent 16 years watching them suffer and die for my scientific career. I'm embarrassed because I didn't take their pain seriously; I'm embarrassed because I forgot about their needs; I'm especially embarrassed because I wasn't bright enough to see the obvious, that all creatures have the right to life without unnecessary exploitation, that all animals, including human animals, are ultimately dependent upon all other life forms for their very existence.

During the many years I worked for the U.S. government, I was required to attend annual courses designed to promote racial equality. At first, they called these mandatory two- or three-day sessions "Race Relations," but, after a time, even the title seemed racist, so they changed it to "Human Relations." I enjoyed these interludes from the ennui of the laboratory, for the discussions and debate centered around values and conditioned perceptions, and, frankly, I loved to watch the racists squirm in their seats. One day, a full-bird Colonel, obviously irritated that his valuable time should be so wasted, blurted out, "I don't care what color a man is, as long as he's an American!"

Ignoring the sexist implication (to which I was not yet attuned), I responded, "Colonel, isn't it time we began thinking in terms of a world community? Isn't nationalism as dangerous as racism?"

He was furious, but said nothing - to me. He did report me to the Commander, however, who reported me to my Division Chief, who reported me to my Branch Chief, and I eventually heard about it. They thought I was a communist! No! Even worse! They thought I was a "nigger-lovin" communist!

Is it wrong to think in terms of a world community? Might that community include other species, other life forms, as well as other humans? 
I'm no longer seen as a "nigger-lovin"" communist. Now I'm seen as an "animal-lovin" misanthropist. Is there really any difference?

I'm not an "animal lover." I know very few animals; some of those I love, most I do not. Some are human; some are not. Isn't it "respect" we're really talking about? After all, I don't have to love you to respect your space; do I have to love other animals to respect theirs?

Do you realize we don't even have enough respect for laboratory animals in our country to count them? We're pretty sure we use between 17 and 70 million laboratory animals each year in the United States. Come to think of it, that rather epitomizes the estimates of error surrounding the use of nonhuman animals as surrogates for humans. How many sets of pliers are issued to Department of Defense mechanics in the United States each year? Who knows? Who cares? I care. You should care.

And pliers don't even feel pain. We do. Other animals do.

Are pliers necessary? No, there are many other tools, such as specialized wrenches, which will do the job better - and countless more which have yet to be designed and built.

Are non-human animals necessary as laboratory tools? No, there are many other tools which will do the job better-and countless more which have yet to be conceptualized and used.

But, I've invoked the concept of "necessity." My opponents insist that the use of non-human animals in medical and biomedical research is absolutely necessary. For humans.

There was a time, not very long ago, when the slave owners in America insisted that the institution of slavery was an absolute necessity for the economic viability of our country. It was "necessary" to drive the Indian from his land, inter all Japanese-Americans during World War II, disallow the vote for women, and use children in the sweat shops of the greedy. It was "necessary" for us to fight in Viet Nam and to attack Libya. Even though the World Health Organization tells us there are 220 drugs required for a nation to sustain its citizens' health and we now have ready access to over 20,000 drugs, we are told of the absolute necessity of using non-human animals to develop even more drugs.

My opponents sputter, "You can't do research on blindness in a test tube! We need intact, functioning systems to be able to understand the interactions of those systems."

What presumptuous statements! Such pronouncements assume we understand the underlying mechanisms of physiological systems. We do not. Such statements imply that we can control all important variables which comprise an intact, functioning system. We can not. In the past when I heard these statements, I used to think my opponents were reading too much Lewis Carroll. Remember? "If you say a thing three times, it must be true." I've now decided they haven't read enough Lewis Carroll, for his jocular absurdities have become their realities. 
"Nonsense!" we are told, "All major medical advances have come through the use of animals in research!" Keeping firmly in mind that all humans are animals, this statement is irrefutable, for the human is always the definitive subject for any experiment relating to human health. Once again, I must remind you that we are operating on an "ends justify the means" argument here. If consistent, the researcher would grant that 100 human subjects would be more efficient than thousands of non-human subjects. If the ends do, indeed, justify the means, then let's get on with it; let's use humans in our experiments to avoid falling into the inextricable morass of extrapolation.

But, perhaps all these arguments are moot. Let's step back and re-examine our ultimate goal: To improve human health. As Steven Tiger (1986) points out, "Making medical progress is not the same thing as improving human health." On the contrary, medical treatment is a relatively unimportant factor in the equation of human health, trailing far behind heredity, lifestyle, and environmental influences. Sociobiological analyses by McKinlay and McKinlay (1977) and McKeown (1976) support this position. McKinlay and McKinlay conclude: "Indeed ...3.5\% probably represents a reasonable upper-limit estimate of the total contribution of medical measures to the decline in mortality in the United States since 1900."

A significant number of respected critics have recently published data which deny that we are winning the war against the most serious and widespread forms of cancer (Bailar and Smith 1986). With the exceptions of childhood leukemia and Hodgkin's disease, two of the rarer cancers, survival rates have really not changed over the last 20 years, despite the suffering and death of hundreds of millions of laboratory animals. A recent monograph by Reines (1986) concludes: "Despite the claims of prestigious scientists, there is no evidence that research on animal models of cancer has ever led to a significant advance in the treatment or prevention of human cancer."

We are all aware that some $30 \%$ of all cancers can be prevented through the cessation of smoking. Another $30 \%$ can probably be prevented by dietary change. Does it not seem logical to revise our priorities, to spend our dollars in preventative education rather than pouring them down the drain with the blood of millions of non-human animals?

Once again quoting from Steven Tiger, "Our research-based sickness-care system is bankrupting the nation, as proven by the fact that pre-set limits to reimbursement are being imposed over the objections of the ultrapowerful medical lobby; there is simply no choice. The medical care industry now costs this nation over $\$ 400$ billion each year, which is far more than the military budget, and it is still growing out of control, like a cancer. What we need in its place is a prevention-based healthcare system; the nation's health would be improved and we could afford to provide far better care than we now can provide to those who would still need it."

I maintain the only "humane" research possible is clinical research, accomplished for the sake of the individual animal being studied. If an individual animal, human or non-human, is suffering, we have an obligation to attempt to alleviate that suffering. If known techniques prove fruitless, 
then let us take the most logical experimental path in treatment, and, through proper documentation and publication of results, share our findings with the rest of the world. "This is always done," you say. Is it?

Every one of us has occasion to visit a physician from time to time. The physician diagnoses, prescribes, and follows the course of your malady. These data disappear into your file, usually forever, dying with the patient or being discarded when one changes physicians. As malpractice suits proliferate, the data are pushed deeper and deeper into the file. Here are data based upon human illness and the response to treatment for that illness. Why is such information discarded in favor of data based on artificial responses of other animals? The answer is simple: These data are not profitable. On the contrary, they are potentially damaging, for they may well reflect misdiagnosis and malpractice.

Fewer and fewer human autopsies are performed each year, and yet autopsies have uncovered a wealth of information in the past. Again, the subject is human, the disease usually identifiable, the progress of the disease unmistakable. I expect none of you would deny that routine autopsy would yield valuable data, and yet autopsies are done for only the most specific of reasons, researchers opting instead to work with laboratory animals. Well, laboratory animals cannot sue, nor can their relatives.

While analyses of patient files and routine autopsies are certainly valuable sources of information, the biomedical community steadfastly maintains that no alternatives to the use of non-human animals are available. We all know that simply is not true. Most of you probably remember that only a few short years ago, a rabbit had to die to confirm human pregnancy. A simple litmus test is now readily available at all drug counters and without prescription. I wonder how the medical lobby allowed that source of funds to slip through their fingers.

I have been told repeatedly by representatives of the medical industry that alternatives cannot be gained by funding programs to discover them. "They occur serendipitously, in the course of research with non-human animals," I am told. Only a few short years ago, the Johns Hopkins Center for Alternatives to Animal Testing (CAAT) was established with funds gained by pressure from the animal rights movement. At last count, nine different alternative procedures to the 40 -year-old Draize Test are ready for validation. The LD-50 Test has been recognized as invalid and anachronistic and is rapidly being replaced by Limit tests and Up-Down procedures. Scientists at CAAT are studying nonanimal alternatives to eye, skin, kidney, and liver research. There is no question that increased funding would speed the progress of these experiments, but the National Institutes of Health (NIH) have never funded a project specifically seeking alternatives to the expensive and invalid use of non-human animals in the laboratory.

Science, the official journal of the American Association for the Advancement of Science, published a Report entitled, "Physiological Correlates of Prolonged Sleep Deprivation in Rats," in the July 8, 1983 issue. Six rats were kept sleepless until death. The conclusion: "... these results support the view that 
sleep does serve a vital physiological function." Well, here's one experiment for which we don't need to find an alternative. Thousands of equally ridiculous experiments are done each year at a staggering cost to the citizens of this country, costs which cannot be measured in dollars alone, but in the futility and immorality of such blatant assaults upon sentient creatures.

Another recent experiment conducted by Fred Van Dyke and published by the Wisconsin Department of Natural Resources, described the capture of 135 mallard ducks as a subject population. Seventy-four of the ducks had one wing broken; the remaining 61 had one wing tied down with leather straps. All were released into the wild or into a pen. The study showed that all but one of the crippled birds released into the wild-and most of those kept in pens-died from starvation, exposure, attacks by predators, or a combination of factors. The conclusion: Crippled ducks die in the wilderness.

On May 28, 1984, members of the Animal Liberation Front (ALF) gained access to the Head Injury Clinic at the University of Pennsylvania and "liberated" over 60 hours of videotapes depicting innumerable violations of the Animal Welfare Act, the experimental protocol, and any standard of humane treatment. These tapes were copied and an edited version was made available to the general public and to elected representatives. Several Congresspersons were outraged and drafted an amendment to deny funding for this laboratory. In a brilliant preemptory move to avoid congressional intervention, the Department of Health and Human Services, in coordination with the NIH, voluntarily closed the laboratory.

Since that time, several other major laboratories have been found wanting and fines have been levied against them, funding withheld, and, in some cases, the laboratories have been closed, at least temporarily. If the medical establishment had been believed, none of these actions would have been taken, for the public has been consistently assured that all is well within the windowless rooms of the experimental laboratories. Is it merely coincidence that each laboratory visited by the ALF was found to be in severe violation of scores of regulations? I doubt it; independent studies by the Office of Management and Budget and the Office of Technology Assessment verify the inadequacy of the existing system to prevent such abuse.

There are no laws to protect laboratory animals from being subjected to the most horrible experiences. There are guidelines, to be sure, and there are specifications for cage size, availability of food and water and other "housekeeping" standards, but any laboratory non-human animal remains completely at the mercy of the experimental protocol. For example, if the researcher makes a case for withholding anesthetics or analgesics, stating that these palliatives will interfere with the results of the experiment, that request will more than likely be approved. There is no appeal process for the laboratory animal.

My point here is simple: The fox guards the henhouse. This is the same fox, by the way, who cited the Head Injury Clinic at the University of Pennsylvania as one of the finest laboratories in the world, only months before the laboratory was closed. Can we afford to leave it to the Animal Liberation 
Front to open public "windows" to these laboratories? I think not; it's time to inform the public, to let them see where their tax dollars go, to take a long and searching look at an archaic and immoral practice.

The state of Florida has established an excellent model with their Sunshine Law. Any citizen of Florida can attend official meetings of state representatives. They may be enjoined from speaking or otherwise disrupting these meetings, but they are authorized to hear all evidence and read all documentation pertaining to the expenditure of public resources.

It was through public atiendance at an Animal Care Connmittee meeting at the University of Florida at Gainesville that we recently learned of a proposal to validate the effectiveness of the Heimlich maneuver for neardrowning victims by anesthetizing, intubating, and nearly drowning 42 random-source dogs. This experiment was approved almost summarily by the Animal Care Committee to be sent forward to the American Heart Association for funding. Another previously-approved proposal was discussed on the same day, this one to suspend cats from pelvic harnesses for periods up to 90 days to study bone remodeling. The public was justifiably outraged; both experiments were subsequently dropped by the University, spokespersons citing reasons other than public pressure. To my mind, all states and the federal government should adopt Sunshine Laws immediately. How can we hope to function effectively as a democratic society if we withhold information from the voters?

"Are there no controls over the researchers?" you ask, and my opponent answers, "Of course! The peer review system is excellent and has long stood the tests of its merit." Peer review, the practice of professionals determining the quality of their fellows' research, has long been a sacred cow to the research industry. But the peer review system is now coming under heavy fire from within. "Even Dr. Stephen Lock, editor of The British Medical Journal, who is one of the staunchest defenders of the principle of peer review, is calling for reform of what he regards as serious defects in a system that has occasionally failed to detect fraud, plagiarism, and simple error" (Altman 1986). The word, "occasionally," is somewhat arbitrary here, for we have no idea how well the system of peer review actually works to prevent duplication or unnecessary experimentation. Given a reliance on peer review, we now have more than one fox guarding all the henhouses.

"So, the system has some flaws," you admit. "How can we best correct its deficiencies?"

Yes, the peer review system is flawed, but that's not the point. Patching up this system to allow continued exploitation of non-human (and human) animals is akin to repairing a faulty gas jet in the showers of Dachau, for it's the system itself which is immoral.

How many of you have read The Case for Animal Rights by Dr. Tom Regan? Before you make up your minds about this issue and put the facts and concepts you'll glean from this conference into little pigeonholes, take the time to read this book. It's a serious philosophical text, well accepted in the academic world, and, along with Peter Singer's Animal Liberation, a major 
foundation for our ethical position. Dr. Regan establishes a strong case for the inherent rights of all animals to exist beyond the unnecessary exploitation of other species. Professor Singer's utilitarian analysis, while espousing completely different arguments from those of Regan, reaches essentially the same conclusion, i.e., we humans have the obligation to adopt a peaceful and humane ethic, to minimize universal suffering of both human and non-human animals. We stand on firm ethical ground and reject the "ends justify the means" argument.

Just over six years ago, I might well have been at a conference such as this upholding my right and obligation to experiment with non-human animals for the sake of humans. Of course, six years ago, conferences like this were nonexistent, but that's another issue. The fact is, six years ago I was detailed by my boss to defuse the concerns of a young Ph.D. statistician who had recently joined our laboratory, and who was appalled that the monkeys were shocked repeatedly during training. My task, you see, was to determine the post-irradiation behavioral effects of pulsed neutron/gamma energy in an effort to predict the effects of nuclear radiation upon military personnel in an operational environment. I had been engaged in this pursuit for some 15 years and was responsible for the suffering and death of over 1,000 rhesus monkeys, as well as a few baboons.

I conferred with our new statistician, telling him of the importance of this information to the military mission of the United States, assuring him of the absence of alternatives, assuaging his concerns with the shopworn litany I expect to hear later today [at this conference]. I convinced him, but, in the process, my words began to sound hollow; I began to unconvince myself. That statistician and I remain friends today, and I credit his sensitivity with forming the first wedge driven between a dormant ethical concern and a highly conditioned "official" scientific position.

I mentioned the sensitivity of this person. Such sensitivity is relatively unusual in an adult male in our society. The animal rights movement is approximately $85 \%$ female, due, I believe, to the fact that our society has allowed females to be empathic and has not conditioned them against feeling or showing sympathy. I remember walking along the San Antonio River about eight years ago and hearing a father trying to comfort his crying son. "Real men don't cry!" he was saying to the boy.

I have already recounted my early conditioning with respect to hunting, trapping, butchering, eating, and wearing non-human animals, but I'd like to say a word about later conditioning. I was taught a fairly rigorous Skinnerian approach to experimental psychology during my graduate days at The Ohio State University. To empathize with the "subject" was a no-no, for that was anthropomorphic and not in keeping with the objectivity required of a real scientist. "Real men don't cry"; real scientists don't either. The animal was a "subject" or a "preparation." Electric shock was a "noxious stimulus" or a "negative reinforcer." Screams were "verbalizations." Starvation was "deprivation." 
I can't begin to tell you how glad I am to be back in the real world of emotion, of animals, of recognizing pain and pleasure, and of respecting the validity of my experience without having to label it with a euphemism.

I was proud of the first draft of my thesis, for I felt it communicated well. My advisor wanted more jargon, and, of course, he got it. The second draft was somewhat more difficult to understand, but still not arcane enough. The third, and final, draft was impossibly difficult but readily accepted. I sometimes have trouble remembering the title-which was, Motive Relevant Perceptual Discriminations of Authoritarians and Non-Autboritarians, or something like that.

To emphasize this condition of irreality in science, allow me to present a short paragraph from the New Scientist, April 10, 1986:

The current issue of Life Sciences contains a paper under the title: "Alternating lateralisation of plasma catecholamines and nasal patency in humans." Our science editor says this means "Why you can breathe up one nostril at a time."

"It's raining pesticides in Hokkaido," is the title of an article in the April 10, 1986 edition of Nature. "Japan may be the first country to be suffering from pesticide rain. There is mounting evidence that pollutants found in Lake Manshu, in the northern island of Hokkaido, may have come all the way from the Chinese mainland before being washed out of the sky. Lake Manshu, often claimed to be the cleanest lake in the world, is 7,000 years old. Benzene hexachloride (BCH) levels are rising precipitously, and will probably continue to rise, for the lake has no outlets and the pesticide is virtually non-biodegradable."

The Washington Post, April 16, 1986: "A University of California professor has accused the Interior Department of suppressing data suggesting that toxic contamination at a California wildlife refuge is moving up the food chain and could pose a threat to endangered species."

The Washington Post, March 4, 1986: "The Agriculture Department listened to testimony from organic farmer, Dick Thompson. Thompson, one of the country's best-known organic farmers, described the non-chemical techniques that have made his Iowa farm a profitable environmental showcase that has taken him out of debt. The secret, he explained, lies in establishing a rotation cycle that helps regenerate soil while blanking out weeds and in using mechanical cultivation at the right time instead of chemicals to combat the weeds that survive. 'This thing is happening everyplace,' Thompson said. 'Both sides-we on the organic side and those on the chemical side-are bending. The ideas of how we have perceived each other are changing.'"

The Washington Post, April 15, 1986: "Hopkins Quits Using Rabbit Tests: In an effort to address the concerns of animal rights groups, Johns Hopkins School of Public Health in Baltimore announced yesterday that it has developed a program to replace using rabbits in eye tests designed to determine irritation from cosmetics and other substances." 
Like Dick Thompson, we see our opposition as bending also. Unlike Thompson, however, we are not satisfied with bending, for each minute sees the irrevocable destruction of between 60 and 100 acres of rain forest and every second of that minute is an eternity of pain to some other animal.

The animal rights movement has progressed far beyond the humane treatment of domestic animals. Listen to the first basic principle of Deep Ecology as defined by Devall and Sessions (1985): "The well-being and flourishing of human and non-human Life on Earth have value in themselves. These values are independent of the usefulness of the non-human world for human purposes."

The July, 1985 issue of Advances in Nursing Science includes an article by Crowley and Conners (1985), "Critique of "The Use of Animals in Nursing Research." The authors state: "Those who would harm animals must justify doing so. To produce such a justification, it is not enough to argue that people profit, satisfy their curiosity, or add to scientific knowledge. These facts are not morally relevant."

Science, April 11, 1986, LETTERS: "Directions of Research," by Richard Trumbull: "It might be that the continued inbreeding of researchers under the protective laboratory conditions now afforded by government support has resulted in another laboratory animal that has lost its resistance and resilience. Here again we might face the problem of finding some researchers 'in the wild' for some imaginative crossbreeding to return our stock to one that can deal with problem-solving in the real world."

The animal rights movement is among the most radical in the world today, for we ask for more than simple prudence or improved housekeeping, or even more stringent controls over the approval and implementation of research projects. We ask for a shift in attitude, the adoption of a more humane ethic, a major revision of conditioned thoughts and behaviors. We ask for a peaceful ethic toward all life forms. We ask for ecological, environmental, and personal respect, and we'll accept no less from ourselves and, eventually, from you.

\section{Endnotes}

'Paper presented at the national conference, "Animals and Humans: Ethical Perspectives," Moorhead State University, Moorhead, MN, April 21-23, 1986.

${ }^{2}$ Director, Washington, DC Office, The National AntiVivisection Society, 112 North Carolina Ave, SE, Washington, DC 20003.

\section{References}

Altman, LK. 1986. Peer review is challenged. New York Times. February 25.

Bailar, JC, III and Smith, EM. 1986. Progress against cancer? New Eng. J. Med. 314: 1226-32.

Crowley, MA and Connors, DD. 1985. Critique of "The use of animals in nursing research." Adv. Nurs. Sci. 7:30.

Devall, B and Sessions, G. 1985. Deep Ecology. Salt Lake City, UT: Gibbs M. Smith, Inc. p.70.

Mckeown, T. 1976. The Role of Medicine: Dream, Mirage or Nemesis. London: Nuffield Provincial Hospitals Trust. pp. 143-44. 
McKinlay, JB and McKinlay, SM. 1977. The questionable contribution of medical measures to the decline of mortality in the United States in the twentieth century. The Milbank Memorial Fund Quarterly/Health and Society. Summer. p.425.

Reines, B. 1986. Cancer Research on Animals: Impact and Alternatives. Chicago: The National Anti-Vivisection Society. p.103.

Tiger, S. 1986. Effective presentation in public debate. The AV Magazine. March. p.7. 